\title{
Gas Flaring in Niger Delta Region of Nigeria: Cost, Ecological and Human Health Implications
}

\author{
Christopher A. Osuoha (Corresponding author) \\ Economics, Applied Statistics \& Intl. Business Dept., New Mexico State University \\ P.O. Box 3051, Las Cruces, NM 88003, USA \\ Tel: 001-575-646-1681Ｅ-mail: cosuoha@nmsu.edu.
}

Michael A. Fakutiju

New Mexico State University, Las Cruces, USA.

Received: August 9, 2017 Accepted: August 31, 2017

doi:10.5296/emsd.v6i2.11662 URL: https://doi.org/10.5296/emsd.v6i2.11662

\begin{abstract}
The study examines the relationship between total gas produced, utilized and flared, also the social cost, economic cost and the public health consequences resulting from gas flaring in the Niger Delta region of Nigeria. The environmental and economic impacts caused by gas flaring activities in this part of the world between 1999 and 2015 were analyzed to establish the relationship gas flaring has with lost economic opportunities, ecological damage and human health challenges. The study examined and discussed the gas flaring cost, the volume of gas produced, public health cost, the cost of pollution abatement technology, social cost-benefit, the regulatory policies, and the reason why oil companies still flare gases. There is no single empirical approach, estimation technique or emission index to quantify the exact impact of gas flaring. The impact of gas flaring on the Niger Delta region is not an assumption but a reality that is supported by verifiable evidence. We find that gas flaring has a devastating impact on human health and the natural ecology. Available cost-effective technological solutions can be deployed by the oil companies to abate the flaring, expand revenue and improve the environmental quality in the Niger Delta area.
\end{abstract}

Keywords: Gas flare, Niger Delta, Ecological degradation, Economic cost, Health impact, Pollution abatement technology, Regulatory policy.

\section{Introduction}

The awareness of the natural environment and the sensitive implication of the damage done 
to the ecology is very critical in creating a balance between the flow of resources from nature to economic activities and the release of residuals from economic activities back to the environment. Petroleum which is pivotal to rapid economic growth and advance in technology enjoyed in the world today has been responsible to a large extent for the devastating environmental damage that has occurred in some parts of the world including the Niger Delta region of Nigeria. Gas flaring involves the practice of burning off the natural gas associated with petroleum into the atmosphere instead of deploying alternative removal methods that are environmentally friendly. Gas flaring is the primary source of anthropogenic pollutants that are responsible for poor air quality, serious public health issues and ecological degradation in this region. Nwaugo et al. (2005), Ifedi and Nwankwo (1989), and Ake (1979) provided evidence that crude oil that naturally occurs as a complex mixture of hydrocarbons comes with extraneous substances including water, gases and inorganic matters. The American Association for the Advancement of Science (AAAS) geospatial survey of the Niger Delta region revealed that gas flaring introduces toxic pollutants such as sulfur dioxide and methane into the atmosphere, which results in environmental problems such as poor air quality, generation of greenhouse gases and chronic respiratory diseases (AAAS, 2015).

According to the World Bank Development Report for 2000/2001, about 110 billion cubic meters (bcm) of gas was flared worldwide in 2000 of which Africa accounted for 37 billion cubic meters $(\mathrm{bcm})$ which are enough to provide a combined annual natural gas consumption of France and Germany (World Bank, 2000/2001). Ismail and Umukoro observed that in 2002 Saudi Arabia, Canada, and Algeria flared 20\%,8\% and 5\% of their natural gas respectively, while Nigeria that is only behind Russia flared $76 \%$ of its natural gas (Ismail \& Umukoro, 2012). Oil and gas companies often use burning for safe disposal of waste gases during process upsets, start- up, shutdown or during operational emergencies while venting is used as a controlled release of gases into the atmosphere during production operations. Tonje Roland explained that some associated petroleum gas (APG) must be flared for safety reasons pointing out that about $45 \%$ of the gas produced is burned on sites in Russia higher than the required secured level (Roland, 2010).

Gas flaring has devastating impacts on biodiversity, air quality and public health. It also constitutes an enormous economic waste. Gas flaring and venting contributes immensely to the emission of greenhouse gas (GHG) whose harmful effect is of global dimension. Air pollution affects air quality which has serious health consequences such as chronic respiratory disease, bronchitis, asthma, reproductive disorder, immune system dysfunction, and other serious health risks that could lead to death. The effect of APG flare is profound on the ecology of the Niger Delta area. Emoyan et al. find that gas flares have adverse effects on the vegetation growth, animal life and ecological equilibrium of the Niger Delta region (Emoyan et al., 2008). Apart from the harmful effects on the ecology and public health, gas flaring is a total economic waste that results in loss of corporate and national revenues. Per Nigerian National Petroleum Corporation (NNPC), gas flaring has been estimated to cost Nigeria over $\$ 2$ billion annually in revenue loss (NNPC, 2014). APG flare above the standard safety level has a devastating consequence that cut across public health, ecology and the economy. 


\section{Literature Review}

Several research works on the impact of gas flaring exist but not many have narrowed their focus on the reasons and the social cost - benefit analysis of flaring. The study discusses not only the public health, ecological and economic consequences of APG flare in the Niger Delta but also made a list of proposals for abatement which gives a fresh perspective on the topic. Additionally, we provided a detail cost analysis of a feasible and viable technological reduction option. Researchers and scholars have published works from different perspectives of natural resources sustainability and environmental economics, and all acknowledged that gas flaring poses a danger to the natural ecology and public health. Gases that could have been harnessed and put to productive use are wasted leading to loss of economic opportunities. The big questions are: (i) what is gas flaring? (ii) what are the economic, environmental and public health impacts? (iii) what financial considerations underpin this practice (iv) What are the technological options to abate gas flaring? (v) Are there regulatory and policy solutions to the problem? The study attempts to provide answers to these questions.

Ite and Ibok explained that flaring and venting APG in the Niger Delta contribute about 35 million metric tons yearly of carbon dioxide $\left(\mathrm{CO}_{2}\right)$, methane $\left(\mathrm{CH}_{4}\right)$ and other forms of GHGs to the region's atmosphere (Ite \& Ibok, 2013). They found that gas flaring contributes to the poor environmental quality and severe human health issues in areas close to the flare sites. The empirical results in Ite and Ibok (2013) were consistent with the results in Ayansina et al. (2010) which suggests that gas flaring contributes to the global climate change and hurts environmental sustainability. Pamela Stokes observed that acid precipitation that leads to acidification is a rising problem that reduces the species richness of an area (Stokes, 1986). Further research by Christiansen and Haugland (2009) found that the issue of flaring has an impact on agriculture and natural forest resulting to ecosystem heat stress and acid rain that accelerate the destruction of freshwater and forest resources. Many communities in the Niger Delta area experience these effects. The effect of APG flare is documented in the literature of natural resource sustainability including topics on the impact of gas flare on the natural ecology, human health, and the economy. Some of the literature including Strosher (2000), Pohl et al. (1986), Karim et al. (1985), and McDaniel (1983) provide perspective on the factors that influence emission, the detection, control, and analytical techniques of the gas flare.

Shore (1996), Kindzierski (1999), Leahey et al. (2001), and Kostiuk et al. (2004) find that emissions from flaring are influenced by factors such as the vent design, operating conditions, and chemical combustion. Ite and Ibok (2013) argued from an operational perspective that about 1.8 billion cubic feet of gas discharged daily in the Niger Delta area is influenced by the energy density of the gas stream, the flare system design, the composition of the gas, and environmental conditions. Their argument is that combustion efficiency depends on the environmental conditions discussed in Strosher (2000), Shore (1996) and Leahey (2001) such as wind speed, stack exit velocity, stoichiometric mixing ratio, and the heating values are seldom successful in realizing complete combustion. The incomplete combustion of the gases generates many volatile organic compounds (VOCs) that wear away the protective waxy 
coating on plant leaves. Odu et al. (1986) find that VOCs deposited on plant leaves, penetrates the leaves and reduce transpiration and photosynthesis turning the leaves yellow or killing the plants in extreme cases.

Other studies on the impact of APG flare on plant and microclimate degradation including Isichei and Sanford (1976), Lawanson et al. (1991) and Dung (2008) find that the toxicity of the contaminant gases affects some aquatic organisms. Gas flare changes the phylogenetic position of marine animals and reduces their sensitivity with an increase in the intensity of gas flare. The thermal pollution from APG flare is reported in Benka-Coker and Ekundayo (1997) to decrease microbial population that is critical in organic matter decomposition and the nitrogen cycle which affects nutrient availability and overall soil fertility. The implication is that the survival of the farmers and fishermen in the Niger Delta areas that depend on the natural environment is in jeopardy if practical steps are not taken to mitigate the ecological risks.

The impact of gas flare on the human health in the region calls for urgent attention. A correlation between certain diseases and levels of exposure to VOCs in communities close to the flare sites has been established in recent studies including Gobo et al. (2009) and Lee et al. (2013). Banerjee and Toledano identified air pollution associated with flaring and venting as the leading cause of chronic health issues such as bronchial, chest, rheumatic and eye diseases (Banerjee \& Toledano, 2016). The consequences of the destructive practice of APG flaring are enormous not only on individual human health level but also on the public health. Amann et al. demonstrated that controlling emission during oil and gas production would substantially reduce premature deaths caused by air pollution (Amann et al., 2017). Evidence in many literature on the impact of gas flares such as Ismail and Umukoro (2012), Roland (2010) and Gobo et al. (2009) show consistency that gas flare has a severe effect on human health.

Flaring of APG is a resource management problem that could be utilized economically. Christiansen and Haugland (2009) noted that gas burning is a waste of resources that have a potential economic value representing great resources management problem. The implication is that the energy deficit faced by Nigeria can be solved by harnessing the APG flared with reckless abandon in the region. The continued shortages in power generation capacity and frequent outages translate to economic losses and untold human hardship. Toledano et al. (2014) observed that flaring had been assessed to cause Nigeria about $\$ 2.5$ billion in forgone revenue between 1970 and 2006. Such lost income could be used to improve the critical state of infrastructural facilities in the Niger Delta. The huge economic loss from APG flare could be converted into corporate profit and government revenue by using appropriate technological solutions. The impact of gas flare transcends across a broad spectrum of ecological, human health, and economic facets of the Niger Delta society.

\subsection{Gas Flaring}

The American Association for the Advancement of Science (2015) described gas flaring as the practice in which the natural gas associated with petroleum is burned off in the atmosphere instead of deploying alternative methods of removal such as subterranean 
re-injection or confinement to storage tanks. ${ }^{1}$ Gas flaring discharges toxic pollutants such as methane and sulfur dioxide into the atmosphere. Methane is a colorless highly flammable gas that is less dense than air which poses immediate or long-term harmful threat to the environment and biodiversity. Methane whose molecular formula is $\mathrm{CH}_{4}$ constitutes the major part of natural gas. The American Association for the Advancement of Science (AAAS) Geospatial Technologies collaborated with Human Rights Project in a survey of the Niger Delta region of Nigeria deploying space borne infrared hotspot detections from 2000 to 2010 and established that when flaring occurs near the inhabited areas, biodiversity is affected.

Gas flaring constitutes direct emission of sulfur dioxide and nitrogen oxide into the atmosphere at a temperature as high as 1,600 degrees centigrade (Adoki, 2012, Ogbuigwe 1998 and Orubu 2002). The U.S. Environmental Protection Agency (EPA) described Sulfur dioxide $\left(\mathrm{SO}_{2}\right)$ as one of a group of highly reactive gasses linked with some adverse effects on the respiratory system. Adoki (2012) observed that temperature as high as $400^{\circ} \mathrm{C}$ at a distance of 43.8 meters recorded from a flare site in Isoko, Delta State in Nigeria has adverse effects on the ecological balance of the area. Adoki claimed that the result of his assessment shows that the levels of concentration of volatile oxides of carbon, nitrogen and sulfur oxides exceeded the Federal Environmental Protection Agency's (FEPA) ambient standards.

\subsubsection{Economic, Environmental and Public Health impact of Gas Flaring}

Gas flaring has enormous negative impact on the local economies of the host communities and the entire Niger Delta region. The gas flared if properly harnessed through conversion into liquid gas or liquefied natural gas (LNG) can create a positive multiplier effect that can boost the local and regional economies regarding job creation and revenue. Most of the gas flared can be converted into household consumable energy or channeled to electricity generation. So, for every thousand cubic feet of gas burned, some dollars or work hours are wasted. Ismail and Umukoro (2012) argued that the economic cost of gas flaring is staggering hence a gas intensive modes of production holds greater opportunities for private sector investment (pp. 293). As a result of the volume of gas flared, the environment is incinerated by raised temperature rendering vast areas of land uninhabitable and non-suitable for agricultural production resulting in high opportunity cost with no Pareto efficient outcome.

Flaring of associated gas poses a grave danger to the natural environment on local, regional and global scales. At the local level, gas flaring hurts the flora and fauna of the host communities. Alakpodia (2000), Odjugo \& Osemwenkhae (2007), and Ismail \& Ezaina (2012), all showed in various studies that flaring affects not only the micro climate but also the soil physicochemical properties. The soils in the areas studied are rapidly losing their fertility and capacity to support sustainable agricultural production due to acidification by the pollutants emitted from flaring. Odjugo \& Osemwenkhae (2007) further observed that sand content of the soil, $\mathrm{pH}$, bulk density, air and land temperature increase towards the flash site and recommended that maize must not be cultivated within 2 Kilometers from the flare site (pp.292).

1 Eyes on Nigeria: Gas Flaring (The American Association for the Advancement of Science; AAAS 2015). 
On the regional level, gas flaring contributes significantly to environmental degradation. Acid rain concentration is higher in Niger Delta region and declines significantly further away from the region. Gas flare produces soot that deposits on building roofs and plant leaves in the area pollutes the soil as the run-off water when it rains. Acid rain has been altering the natural vegetation and environmental quality in Niger Delta.

Gas flaring and venting produces Methane $\left(\mathrm{CH}_{4}\right)$, Carbon dioxide $\left(\mathrm{CO}_{2}\right)$ and Sulfur dioxide $\left(\mathrm{SO}_{2}\right)$ which increase the concentration of GHG resulting in the depletion of the ozone layer that impact negatively on the global environment. EPA explained that greenhouse gas contributes immensely to global warming and climate change by making the planet warmer and thickening the earth's blanket (U.S. Environmental Protection Agency, 2014). The EPA (2014) argues that if flaring remains unchecked, the consequences of climate change and harsh living condition will exacerbate and the global environmental quality will be compromised.

\subsubsection{Economic Considerations That Underpin Gas Flaring}

Many kinds of literature on gas flaring reviewed gave similar reasons why most oil and gas companies chose to flare associated gas. Justice in Nigeria Now - a Non-Governmental Environmental Protection Organization is confident that the reason why oil companies burn gas in the Niger Delta region is that it is the cheapest way to separated crude oil from associated natural gas. ${ }^{2}$ Gas flaring has been illegal in Nigeria since January 1984 when the federal government of Nigeria set the first target date for zero flares via Associated Re-Injection Act of 1979, but unfortunately, oil companies persisted to flare preferring to pay fines many consider too little. The Act allowed some conditions for certain exemptions or payment of a penalty which was fixed at US\$0.003 per million cubic feet in 1984 but subsequently increased over time and most recently in 2008 to US\$ 3.5 for every standard 1000 cubic feet. The low-level of punishment is the primary cause of the unabated practice of flaring gas because the penalty is so little that it does not justify the massive investment to stop the flaring even when abatement is economically viable.

Three different reasons were given by Clean Air Taskforce (2015) for gas flaring in the U.S. tight oil fields such as the Bakken formation in North Dakota and the Eagle Ford in Texas. ${ }^{3}$ According to Clean Air Taskforce, the three reasons include:

(a) safety reasons to dispose of gases during a particular oil well development and maintenance activities such as commissioning, start-up, short-down, and routine or non-routine maintenance.

(b) Lack of gas utilization capacity due to isolated well flaring that has no connection to the gas gathering system.

2 Why Oil companies flare gas (Justice in Nigeria Now 2010). See http://justiceinnigerianow.org/gas-flaring.

3 Tight oil is a medium-to-light grade oil produced from very low permeability formations in which oil and gas flow within the rock formation is limited. See (Clean Air Taskforce, 2015). 
(c) Lack of pipeline or compression capacity to capture the gas flare into the utilization system.

\subsubsection{Technological Options to Abate Gas Flaring}

Several technological options are available to oil and gas companies to abate gas flaring and explore the product value chain of associated gas flared. There are critical factors that determine the most efficient and economic viable technology to deploy. According to Clean Air Taskforce, critical factors such as technical, geographical and commercial factors determine the best utilization option suitable for an oil and gas production facility (Clean Air Taskforce,2015). The type of oil formation determines the variability of the composition, flow rates, and pressures that the utilization option should have the technical capability to handle. The geographical location of production is crucial in determining the feasibility of connecting flow stations to remote gathering systems or electric grid. Commercial factors may be the greatest challenge in conveying gas or electricity to the market because the feasibility of a particular utilization technology varies with locations, corporate characteristics and market demand for products. The composition of gas has better economic returns when the gas is rich with heavier hydrocarbons such as ethane, propane, butane and other heavier compounds that can be separated and marketed separately.

The feasibility of the technology option lies on nine primary process assessment criteria recommended by Clean Air Taskforce (2015) which include Ammonia production, compressed natural gas (CNG) trucking, and natural gas liquids (NGL) recovery. Others are the gas injection to underground reservoirs, gas-to-power (grid), gas-to-power (local), and gas-to-liquids; methanol (GTL-MT). The remaining methods are gas -to- liquid - Fischer Tropsch for clean diesel (GTL-FT) and liquefied natural gas (LNG) (p.12). On a different study of Russia, Kazakhstan, Turkmenistan, and Azerbaijan, Carbon Limits AS, recommended five basic technological solutions which include: Associated Petroleum Gas (APG) gathering system, gas treatment and processing, on-site use, conversion processes and transport options (Carbon Limits AS, 2013). The conversion process is an ideal solution for oil companies operating in Niger Delta because of the long product value chain of the associated gas in the region.

\subsubsection{Regulatory and Policy Solutions}

Regulatory policy and relevant legislation are potent tools in gas flaring abatement. This approach has not been successful in the Niger Delta because of failure to implement regulatory policies or enforce anti-gas flare legislations. Ukala (2011) explained that the federal government of Nigeria recognized the use of legislative measure as a powerful tool to end gas flaring and enacted relevant legislations such as the Petroleum Act of 1969 and Associated Gas Re-Injection Act No.99 of 1979. Characteristically like numerous legislations in the country, the regulations have not achieved any significant result because gas flaring remained a widely practiced activity in Niger Delta. Several target dates for implementation of gas flaring in Nigeria has been set, but they are either extended or exempted.

Carbon Limits (2013) explained that in line with the principle of cost efficiency, regulatory 
authorities should set targets and requirements based on specific circumstances, pointing out that the major challenge of this approach is asymmetrical information between resource owners and the regulators (p.69). Both Ukala (2011) and Carbon Limits (2013) concluded that despite improvement in regulatory practice significant inefficiencies exist. The Niger Delta situation is exacerbated by unrealistic broad base target, prescriptive approaches, and inconsistent enforcement mechanism.

\section{Theoretical Model}

The theoretical framework of gas flaring is based on the quantity of gas produced and the amount of that volume utilized. The closest theoretical foundation to analyze this concept is in Feldman et al. (1982) that attempts to explain the energy release mechanism of the solar flare described in Zirin et al. (1981). The analysis in Zirin et al. (1981) used the temporary behavior of the soft X-ray (SXR) and hard X-ray (HXR) event and observation at a visible wavelength to determine the source of emission and the region impacted by the flare. The volume of the solar flare determines the strength and the impact of the radiation and whether the proportion has soft or hard behavior. The focus of recent literature on gas flare has been on the property of the gases flared and their ecological implications. We consider it necessary to establish the theoretical foundation as the basis for developing the empirical model. The implication is that the quantity of gas flare is the function of the gas produced and utilized. We used both econometric model and descriptive statistics to analyze gas flaring in the Niger Delta. The econometric model is:

$$
\begin{gathered}
\mathrm{GF}=f(\mathrm{GP}, \mathrm{GU}) \\
\mathrm{LN} \_\mathrm{GF}=a+b 1 \text { LN_GP }+b 2 \mathrm{LN} \_\mathrm{GU}+\mu
\end{gathered}
$$

This is Log Linear Model where:

LN_GF is the log of Gas Flared, LN_GP is log of Gas Produced and LN_GU is log of Gas Utilized, $a$ is constant.

\subsection{Data, Methodology and Estimation}

Data on volume of gas produced, utilized and flared was generated directly from a reliable primary source - the monthly petroleum information (MPI) bulletin of the Nigerian National Petroleum Corporation (NNPC) while information on natural gas prices was generated from the U.S. Energy Information Administration (EIA). We obtained the population figures and mortality rate from the 2006 census data and crude death rate reported by the National Bureau of Statistics (NBS) of the Federal Republic of Nigeria and the National Population Commission (NPC) of Nigeria. Capital Expenditure (CAPEX), Operating Expenses (OPEX) and Net Present Value (NPV) were estimated based on cost information of the largest Gas-toLiquid (GTL) facility in Nigeria own by Chevron Nigeria. The CAPEX, OPEX, and NPV of the $\$ 10$ billion project that began production in mid-2014 were used in analyzing the cost benefit which served as the basis of our proposal. 


\subsection{Data Description}

The data used were monthly data from 2007 to 2015 which is time series data, and our number of observation is 90 (90 months). The data is generated from the Nigeria National Petroleum Corporation's Monthly Petroleum Information (MPI) figures. Data were collected on gas produced, utilized and flared for the period under observation.

\subsection{Methodology}

We test for both the short and the long run relationship among the variables. (Gas produced, utilized and flared). Because our data is a time series data, Augmented Dickey-Fuller test statistic was used to test for the unit root, the variables could be stationary or non-stationary because if they are not stationary and we fail to correct that, it can lead to spurious regression that will yield a misleading regression result.

Augmented Dickey-Fuller test statistic

We did the unit root test under the null hypothesis $\gamma=0$

And the alternative hypothesis of $\gamma<0$.

Where Null Hypothesis Ho: shows that the variable has a unit root.

Alternative Hypothesis Ha: The variable does not have a unit root.

The testing procedure for the ADF test is:

$$
\Delta y_{t}=\alpha+\beta t+\gamma y_{t-1}+\delta_{1} \Delta y_{t-1}+\cdots+\delta_{p-1} \Delta y_{t-p+1}+\varepsilon_{t}
$$

$\alpha$ : Constant

$\beta$ : Coefficient on a time trend

$p$ : The lag order of the autoregressive process.

We have to Impose the constraints $\alpha=0$ and $\beta=0$

Empirical Results.

Table 1. Unit Root Test

\begin{tabular}{|l|l|l|r|l|l|l|}
\hline \multicolumn{2}{|l|}{ Levels } & First Difference \\
\hline Variables & ADF-Statistic & Lag & Variables & ADF-Statistic & Lag & $I(0)$ \\
\hline $\operatorname{lnGF}$ & $-1.412943[0.5716]$ & 5 & $\Delta \operatorname{lnGP}$ & $-9.100043[0.0000]^{* * *}$ & 2 & $I(1)$ \\
\hline $\operatorname{lnGP}$ & $-2.468388[0.1266]$ & 2 & $\Delta \operatorname{lnGP}$ & $--9.207375[0.0000]^{* * *}$ & 2 & $\mathrm{I}(1)$ \\
\hline $\operatorname{lnGU}$ & $-2.847446[0.0558]$ & 1 & $\Delta \operatorname{lnGU}$ & $-10.51598[0.0000]^{* * *}$ & 1 & $I(1)$ \\
\hline
\end{tabular}

Levels of Significant: $* \mathrm{p}<0.1, * * \mathrm{p}<0.05, * * * \mathrm{p}<0.01 . \Delta$ refers to first difference, while $I(0)$, means the order of integration. Our $\mathrm{p}$ values are put in parenthesis.

Source: Computed by the authors using E views 8.0 Package.

The unit root test above shows that all the variables were not stationary at levels. This can be seen from the $\mathrm{p}$ value of Augmented Dickey -Fuller test statistic which is not statistically 
significant. But when we took the first difference of the variables, they were statistically significant at one percent level of significance with $p<.0000$ for all the variables.

Table 2. Diagnostic Tests

\begin{tabular}{|l|l|l|}
\hline Test Statistics & LM Version & F version \\
\hline A: Serial Correlation & CHSQ $(12)=14.6361[.262]$ & $\mathrm{F}(12,59)=1.2122[.297]$ \\
\hline B: Functional Form & CHSQ $(1)=.63444[.426]$ & $\mathrm{F}(1,70)=.065331[.439]$ \\
\hline C: Normality & $\mathrm{CHSQ}(2)=60.0409[0.000]$ & Not applicable \\
\hline D: Heteroscedasticity & $\mathrm{CHSQ}(1)=1.2034(.273)$ & $\mathrm{F}(1,72)=1.19031[.279]$ \\
\hline
\end{tabular}

Source: Computed by the authors using E views 8.0 Package.

A: Lagrange multiplier test of residual serial correlation, B: Ramsey's RESET test using the square of the fitted values, C: Based on a test of skewness and kurtosis of residuals

D: Based on the regression of squared residuals on squared fitted values.

Our $\mathrm{p}$ values are in parenthesis.

The results show that there is no serial correlation and heteroscedasticity in our model.

Hypothesis:

1. Test for the relationship between gas produced and gas flared.

Where Log of gas flared is the dependent variable, and log of gas produced is the independent variable.

Ho: $\mu=0$ : There is no relationship between gas produced and gas flared.

Ha: $\mu \neq 0$ : There is a relationship between gas produced and gas flared.

2. Test for the relationship between gas utilized and gas flared.

Where Log of gas flared is the dependent variable, and log of gas utilized is the independent variable.

Ho: $\mu=0$ : There is no relationship between gas utilized and gas flared.

Ha: $\mu \neq 0$ : There is a relationship between gas utilized and gas flared.

Table 3. Estimated Long run coefficients using ARDL Approach

Dependent variable: log of Gas Flared. (74 observations used for the estimation.

\begin{tabular}{|l|l|l|}
\hline Independent Variables & Co-efficient. & P values \\
\hline LGP & $2.4761(7.7523)^{*}$ & $<0.000$ \\
\hline LGU & $-1.4662(-6.6060)^{*}$ & $<0.000$ \\
\hline INPT & $-2.1085(-0.79809)$ & $<.427$ \\
\hline
\end{tabular}

$\mathrm{T}$ statistics in parenthesis 


\section{Ml Macrothink}

Levels of significant: $* \mathrm{p}<0.1, \quad * * \mathrm{p}<0.05, * * \mathrm{p}<0.01$

Source: Computed by the authors using E views 8.0 Package.

From the regression result, LNGP is positive and significant with $\mathrm{p}$ value of $<.000$ which is less than our $\alpha$ value 0.05 . Therefore, we reject Ho. And concluded that there is a relationship between the gas produced and gas flared. The coefficient of Log of gas produced is positive, this means for every one percentage increase in gas produced, there is corresponding 2.47 percentage increase in gas flared. Again, LNGU is negative and significant, the $p$ value is $<.000$ which is less than the $\alpha$ value of 0.05 . Therefore, we reject Ho. And conclude that there is a relationship between the gas utilized and gas flared. The coefficient of Log of gas utilized is negative, this means for every one percentage increase in gas utilized, there is a corresponding 1.4 percentage decrease in gas flared. There is no short run relationship between the variables, because the error correction model is not significant.

\subsection{Descriptive Statistics}

We used descriptive statistics because of the limitation of the available health data in the local communities of the Niger Delta. Consequently, we collected data on national and states' Crude Death Rate in percentages (Mortality rate) for Nigeria between 2001 and 2005 from Nigerian National Bureau of Statistics' (NBS's) database. Nigeria is made up of 36 states with Federal Capital Territory (FCT) making 37 administrative units. Mortality rates from 13 states (states with civil unrest or states with poorly developed health facilities) were removed, so the figures from these states will not bias our result. Comparing the national mortality rates with the individual states mortality rates from 2001 to 2005 , we found out that the mortality rates for the oil producing states were higher on average than non-oil producing states. From our analysis, states with more onshore wells than offshore wells have higher mortality rates among the oil producing states.

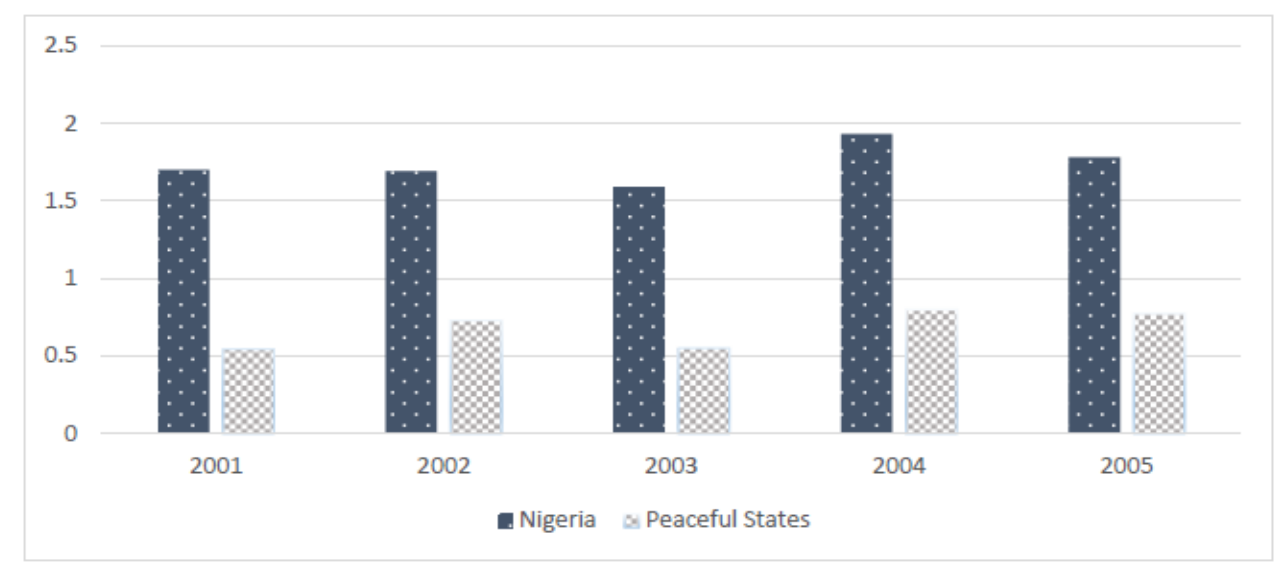

Figure 2. Yearly average of the \% mortality rate in Nigeria with Peaceful States' average

Source: Computed by the authors using National Bureau of Statistics and Federal Republic of Nigeria \& National Population Commission, Nigeria - 2006 Census data.

The graph in figure 2 above shows that the Nigerian average mortality figures are well above 


\section{Macrothink}

those of the peaceful states for the same period.

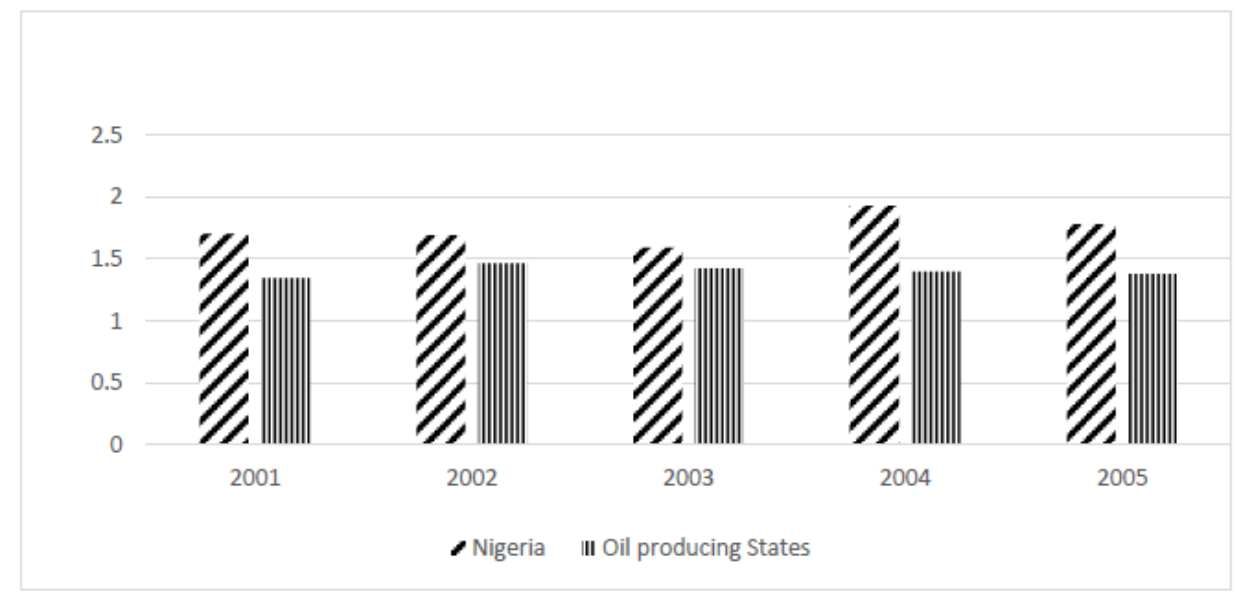

Figure 3. Yearly average of the \% mortality rate in Nigeria with Oil Producing States' average

Source: Computed by the authors using National Bureau of Statistics and Federal Republic of Nigeria \& National Population Commission, Nigeria - 2006 Census data.

Figure 3, shows that yearly averages of the percentage mortality rate in Nigeria from 2001 to 2005 is close to that of the oil producing states where gas flaring occur for the same period.

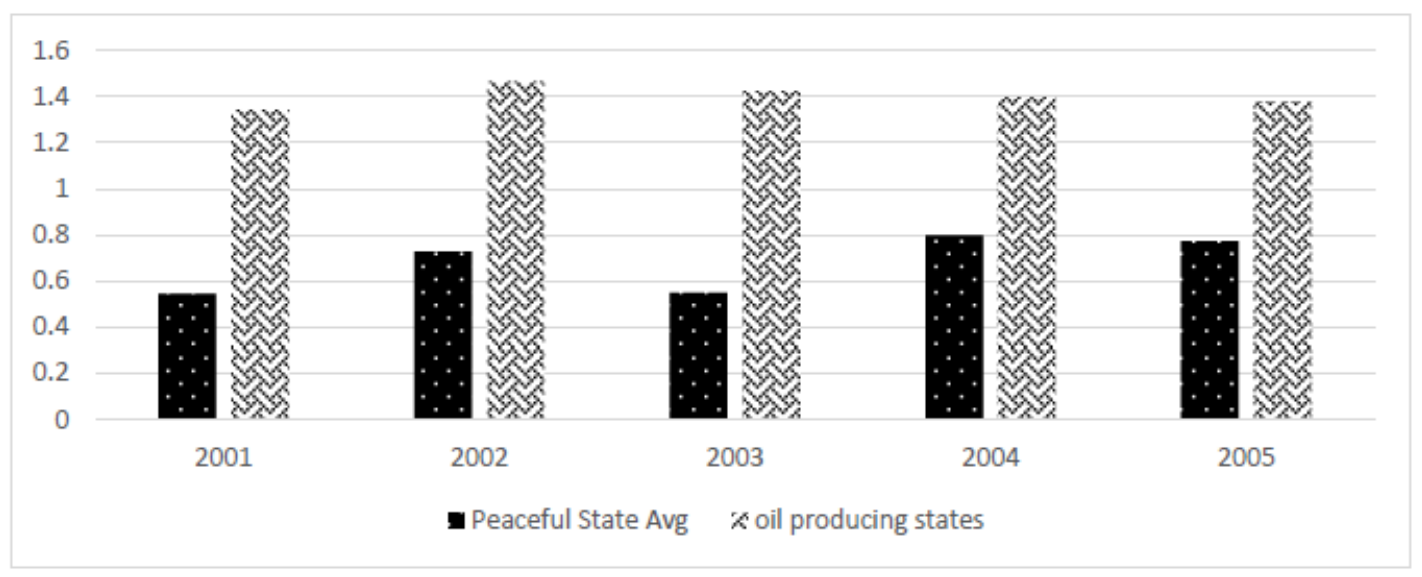

Figure 4. Figure 1: Percentage mortality rate in Nigeria from 2001 to 2005 measured against those of the peaceful states

Source: Computed by the authors using National Bureau of Statistics and Federal Republic of Nigeria \& National Population Commission, Nigeria - 2006 Census data.

From Figure 5 above, the yearly averages of the percentage mortality rate in the gas flaring states are well above that of in the peaceful states. 


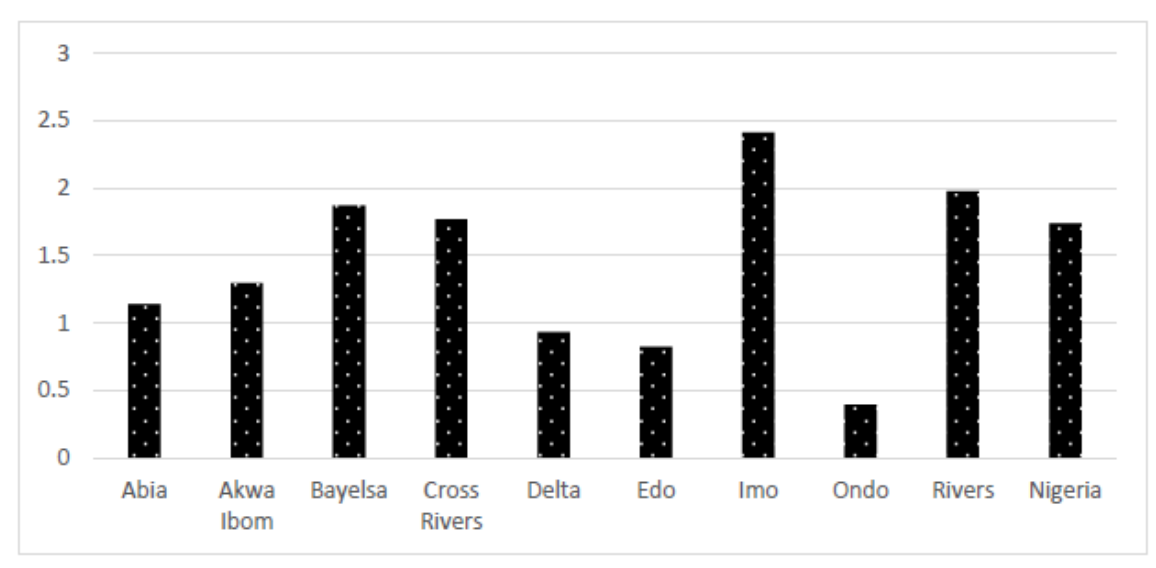

Figure 5. Five Year Average

Source: Computed by the authors using National Bureau of Statistics and Federal Republic of Nigeria \& National Population Commission, Nigeria - 2006 Census data.

In Figure 5, we took the 5-year average of the percentage mortality rates of each of the oil producing states and compared it with that of the national average. We found out that states with more oil wells and states with more onshore wells than offshore wells have higher mortality rates compare to states with lesser oil wells or fewer onshore wells.

\subsection{Cost Estimation and Benefit Analysis}

Cost effectiveness, technical feasibility, and profitability are the principal considerations in the execution of projects. It is evident that well-managed firms go to a great extent to develop good capital budgeting proposals to improve existing products and operate more efficiently. Cost estimation helps an organization in developing operating plans and optimal capital budget.

The cost estimate and benefit analysis are based on the total project cost of $\$ 10$ billion which represents the capital expenditure (CAPEX). The project has a payback period of 20 years, annual operating expenses (OPEX) of $38 \%$ of gross revenue, the daily production capacity of 33,000 barrels of synthetic diesel. The 1-year average price of clean diesel from June 2014 when the plant started production to July 2015 and the discount rate between 5\% and 15\% which is the conventional range of cost of borrowing to finance the project of this magnitude were applied. The facility operates 346 days in a year leaving 21 days for routine maintenance. The facility is designed to increase daily production capacity to 120,000 barrels per day after 10 years of operation. Based on this information we estimated gross revenue, operating cost (OPEX), profit, amortization, and the NPV at a discounted rate of 5\%,10\%, 12\% and $15 \%$ over a payback period of 20 years.

\section{Capital Expenses (CAPEX): Fixed Cost at \$10 Billion}

2. Gross or Total Revenue (TR)

$T R=\operatorname{Price}(P) *$ Output $(Q)$, 


\section{Macrothink}

Where $\mathrm{P}$ is the price of synthetic diesel in barrels ( 1 barrel is equivalent of 42 gallons which is sold at $\$ 3.38175$ per gallon) and $\mathrm{Q}$ is the daily production of synthetic diesel (33,000 barrel) for 346 days.

$$
\begin{gathered}
T R=P * Q \\
\mathrm{TR}=(42 * 3.38175) *(33000 * 346)=\$ 1621356000.00
\end{gathered}
$$

The gross annual revenue for the first 10 years is $\$ 1621356000.00$ per annum. The gross revenue will increase after 10 years of operation. So, the annual income from the $11^{\text {th }}$ year to the $20^{\text {th }}$ year will be $\$ 5895840000.00$ per annum as shown below.

$$
\mathrm{TR}=(42 * 3.38175) *(120000 * 346)=\$ 5895840000.00
$$

\section{Operating Expenses (OPEX)}

The annual operating expenses is fixed at $38 \%$ of annual gross revenue. So, for the first 10 years the OPEX will be $38 \%$ of annual TR for the first 10 years.

$$
\mathrm{OPEX}=\mathrm{TR} * 38 \%=\$ 1621356000.00 * 38 \%=\$ 616115280.00
$$

For the last 10 years that is from $11^{\text {th }}$ year to the $20^{\text {th }}$ year the OPEX will increase to $\$ 2240400000.00$ as shown below.

$$
\mathrm{TR} * 38 \%=\$ 5895840000.00 * 38 \%=\$ 2240400000.00 .
$$

\section{Profit}

Profit ( $\pi)$ is annual total revenue (TR) less OPEX. For the first 10 years, profit will be

$\$ 1005200000.00$ per annum as shown below.

$$
\pi=T R-O P E X=\$ 1621356000.00-\$ 616115280.00=\$ 1005200000.00 .
$$

Profit in between the $11^{\text {th }}$ year and $20^{\text {th }}$ year will be $\$ 3655400000.00$ per annum.

$$
\pi=T R-O P E X=\$ 5895840000.00-\$ 2240400000.00=\$ 3655400000.00 .
$$

5. Net Present Value (NPV)

Net present value (NPV) is the present value of a project's cash flows minus the present value of its costs which shows how much the project contributes to shareholder's wealth. The principal approach is that the larger the NPV, the more the value the project adds to the overall corporate value of the firm. The project NPV is calculated applying the standard formula using four discount rates of $5 \%, 10 \%, 12 \%$ and $15 \%$ over a payback period of 20 years.

$$
N P V=\left[C F_{1} /(1+r)^{1}+C F_{2} /(1+r)^{2}+\ldots \ldots .+C F_{N} /(1+r)^{N}\right]-\text { Initial Cost. }^{4}
$$

Where $\mathrm{CF}_{\mathrm{N}}$ is the project cash flow.

\footnotetext{
${ }^{4}$ NPV of Project. See: (Ehrhardt \& Brigham ,2011. P.381)
} 
$\mathrm{N}$ is time (year) equal to 1,2 .20 .

$\mathrm{r}$ is the discount rate $(5 \%, 10 \%, 12 \%$ and $15 \%)$.

Initial Cost is $\$ 10$ billion.

The cash flow for the first 10 years is a single stream of annual inflow of \$1 621356000.00 while cash flow from 11th year to the 20th year is a different amount of single stream of inflow as result of an increase in production capacity of the GLT facility after 10 years of operation. The estimation relies on the expected capabilities of $100 \%$ which will drive production at near $100 \%$ capacity. The NPV took into consideration loan repayment which is amortized over the payback period of 20 years. The detail calculation of the gross revenue, profits, loan amortization, and NPV at 5\%,10\%, 12\% and 15\% discount rates are shown in the spreadsheet shown in table 3 below. The NPV at 5\%,10\%, and $12 \%$ were positive while NPV at $15 \%$ was negative.

Table 3. CAPEX, OPEX, Profit, Amortization and NPV of the GLT Facility.

\begin{tabular}{|l|l|l|l|l|l|l|l|l|l|}
\hline $\begin{array}{l}\text { Time } \\
\text { (year) }\end{array}$ & $\begin{array}{l}\text { CAPEX } \\
(\mathrm{B} \$)\end{array}$ & $\begin{array}{l}\text { OPEX } \\
(\mathrm{B} \$)\end{array}$ & $\begin{array}{l}\text { Gross } \\
\text { Rev.(B } \$)\end{array}$ & $\begin{array}{l}\text { Profit } \\
(\mathrm{B} \$)\end{array}$ & $\begin{array}{l}\text { Amortization } \\
(\mathrm{B} \$)\end{array}$ & $\begin{array}{l}\text { NPV } \\
5 \%\end{array}$ & $\begin{array}{l}\text { NPV } \\
10 \%\end{array}$ & $\begin{array}{l}\text { NPV } \\
12 \%\end{array}$ & $\begin{array}{l}\text { NPV } \\
15 \%\end{array}$ \\
\hline 0 & -10 & 0 & 0 & 0 & -10 & -10 & -10 & -10 & -10 \\
\hline 1 & 0 & 0.6161 & 1.6214 & 1.0052 & -8.9948 & 1.0052 & 1.0052 & 1.0052 & 1.0052 \\
\hline 2 & 0 & 0.6161 & 1.6214 & 1.0052 & -7.9895 & 1.0052 & 1.0052 & 1.0052 & 1.0052 \\
\hline 3 & 0 & 0.6161 & 1.6214 & 1.0052 & -6.9843 & 1.0052 & 1.0052 & 1.0052 & 1.0052 \\
\hline 4 & 0 & 0.6161 & 1.6214 & 1.0052 & -5.9790 & 1.0052 & 1.0052 & 1.0052 & 1.0052 \\
\hline 5 & 0 & 0.6161 & 1.6214 & 1.0052 & -4.9738 & 1.0052 & 1.0052 & 1.0052 & 1.0052 \\
\hline 6 & 0 & 0.6161 & 1.6214 & 1.0052 & -3.9685 & 1.0052 & 1.0052 & 1.0052 & 1.0052 \\
\hline 7 & 0 & 0.6161 & 1.6214 & 1.0052 & -2.9633 & 1.0052 & 1.0052 & 1.0052 & 1.0052 \\
\hline 8 & 0 & 0.6161 & 1.6214 & 1.0052 & -1.9580 & 1.0052 & 1.0052 & 1.0052 & 1.0052 \\
\hline 9 & 0 & 0.6161 & 1.6214 & 1.0052 & -0.9528 & 1.0052 & 1.0052 & 1.0052 & 1.0052 \\
\hline 10 & 0 & 0.6161 & 1.6214 & 1.0052 & 0.0525 & 1.0052 & 1.0052 & 1.0052 & 1.0052 \\
\hline 11 & 0 & 2.2404 & 5.8958 & 3.6554 & 3.7079 & 3.6554 & 3.6554 & 3.6554 & 3.6554 \\
\hline 12 & 0 & 2.2404 & 5.8958 & 3.6554 & 7.3633 & 3.6554 & 3.6554 & 3.6554 & 3.6554 \\
\hline 13 & 0 & 2.2404 & 5.8958 & 3.6554 & 11.0188 & 3.6554 & 3.6554 & 3.6554 & 3.6554 \\
\hline 14 & 0 & 2.2404 & 5.8958 & 3.6554 & 14.6742 & 3.6554 & 3.6554 & 3.6554 & 3.6554 \\
\hline 15 & 0 & 2.2404 & 5.8958 & 3.6554 & 18.3296 & 3.6554 & 3.6554 & 3.6554 & 3.6554 \\
\hline 16 & 0 & 2.2404 & 5.8958 & 3.6554 & 21.9850 & 3.6554 & 3.6554 & 3.6554 & 3.6554 \\
\hline 17 & 0 & 2.2404 & 5.8958 & 3.6554 & 25.6404 & 3.6554 & 3.6554 & 3.6554 & 3.6554 \\
\hline 18 & 0 & 2.2404 & 5.8958 & 3.6554 & 29.2959 & 3.6554 & 3.6554 & 3.6554 & 3.6554 \\
\hline 19 & 0 & 2.2404 & 5.8958 & 3.6554 & 32.9513 & 3.6554 & 3.6554 & 3.6554 & 3.6554 \\
\hline 20 & 0 & 2.2404 & 5.8958 & 3.6554 & 36.6067 & 3.6554 & 3.6554 & 3.6554 & 3.6554 \\
\hline & & & & & 25.0907 & 14.8365 & 12.3299 & 9.5799 \\
\hline & & & & & & -10.0000 & -10.0000 & -10.0000 & -10.0000 \\
\hline Net Present Value (NPV) & & & & 15.0907 & 4.8365 & 2.3299 & -0.4201 \\
\hline
\end{tabular}

NPV Decision Rules: for independent projects if NPV exceeds zero and is positive accept the project, where projects are mutually exclusive accept the project with higher NPV. ${ }^{5}$

\footnotetext{
${ }^{5}$ NPV decision rules (Ehrhardt and Brigham 2011. P.386).
} 


\section{Discussion of Empirical Result, Cost \& Benefit Analysis}

The regression analysis shows that the coefficient of Log of gas produced is positive which implies that for every one percent increase in gas produced, there is a corresponding 2.47 percentage increase in gas flared. The meaning is that growth in the volume of gas produced without deploying abatement technology causes more discharge of APG into the atmosphere in the region. Without a commitment by the government in implementing efficient regulatory policies the end of flaring will remain far from sight. Also, the coefficient of Log of gas utilized is negative; this means that for every one percent growth in gas used, there is a corresponding 1.4 percentage decrease in gas flared. High utilization of gas produced will reduce the volume of gas burned. The impact of the increased capacity use of gas production will enhance the environmental quality, reduce the incidences of human health issues and improve both corporate revenues of the firms and the government's tax-base. Nigeria can take a similar approach as Kazakhstan did in the Kashagan and Tengiz regions by amending and reviewing the existing petroleum legislations for abating APG flare reported in Ch. Lee (2013) and Foster (2010). A realistic arrangement can be made between oil companies and regulatory agencies to allow the firms to transition to abatement programs. The reason is that the empirical results suggest that the solution to gas flare lies on the increase utilization of gas produced.

The result of the analysis of the descriptive statistics suggests that there is a strong relationship between the volume of gas flared and the reported crude death in the states that constitute the Niger Delta region. Although, correlation is not causation, the relationship between the amount of gas burned and reported number of fatalities is strong. The average percentage of mortality rate of the oil producing states in the Niger Delta area compared to the national averages indicates that the difference is small compared to the disparity between the peaceful states and the national average. The national crude death rate average is high because of the activities of the Islamist extremist group - Boko Haram in the Northeastern part of Nigeria. The Boko Haram menace seem to distort the actual mortality trend in the country hence the stable states referred to as the peaceful states are used as a preferable benchmark to compare the reported crude death trend. The analysis gave a clearer picture of the effect of APG flare when the states in the Niger Delta region were compared to the peaceful states. The comparison of the oil producing states to the peaceful states shows a big disparity in crude death rate.

A 5-year average of the percentage mortality rates of the nine oil producing states and Nigeria shows that the crude death rate in four oil producing states including Imo, Rivers, Bayelsa, and Cross River are higher than the national average. The trend is rationalized by the difference in the reported crude death rate between the states with more onshore oil wells and those that have less onshore well but more offshore wells. The results showed that the four states (Imo, Rivers, Bayelsa and Cross Rivers) that have greater number of onshore flare sites have higher death rate than others with fewer flare sites. Therefore, there is a vivid evidence to infer that gas flare has serious public health consequences and negative impact on the natural ecology of the region. In a related study van Dessel and Omuku find that there is a causal relationship between the environment and the activities of the oil and gas companies 
(van Dessel \& Omuku, 1994). The finding in Urbaniak et al. (2007) reinforces this evidence. According to Urbaniak et al. and Lee et al. cardiovascular diseases, respiratory tract diseases, anaemia, leukaemia, premature delivery and cases of embryo death are linked to gas flaring (Urbaniak et al., 2007 \& Lee et al., 2013). Although, the claims are subject to more scientific research but they are consistent with the analysis of the descriptive statistics.

The cost estimation and benefit analysis shows that the abatement technology option- the GTL is feasible. With an operating capacity near $100 \%$ the GTL facility cost can be paid off before 20 years at any rate between $5 \%$ to $12 \%$ financing. The oil companies should be encouraged to take advantage of GTL because on the long-run it is economically viable and cost-effective. It is not only profitable but will help in reducing the impact of APG flare on human health and the environment.

\subsection{Proposal for a Technological Abatement Option.}

Based on the results of the NPV, the technological option (GTL), economic viability (profit) and maximization of the social welfare of the people of Niger Delta we make the following proposals:

1. That the establishment of gas-to-liquid (GTL) technology will provide cost-effective and technically efficient solution to reduce gas flaring by conversion of flared gas into synthetic diesel that is in high demand locally and internationally.

2. Oil and gas companies should explore utilization of associated gas via GTL to internalize social cost and improve corporate revenue. Financing an investment of this size at a social discount rate of 5\% will enable oil companies to discharge their corporate social responsibilities to the host communities. They can provide infrastructure, build healthcare centers and provide potable drinking water to the host communities to maintain a sustainable relationship with the local communities.

3. Oil and gas companies can explore GTL as pollution abatement strategy to reduce pollution, reduce environmental degradation, improve public health and comply with legal and regulatory requirements.

4. Gas utilization technology such as GTL will create high-quality jobs that will improve the local economies in Niger Delta region and provide a stable tax base for the federal and state governments.

5. Establishing GTL will stabilize the strong agitation by the people of Niger Delta, reduce the damage to the environment and avoid constant disruption of production and oil pipeline vandalism that is associated with the region. The approach will help oil companies stabilize the local economies and lower their production cost.

6. GTL will allow oil and gas companies to develop a strong value chain that can leverage backward and forward linkages that can create direct and indirect jobs that will enhance the economic development at the local, regional and national levels as well as increase corporate value. 


\section{Summary}

The volume of gas produced has a direct relationship with the amount of APG utilized and flared. The more the amount of gas produced, the greater the volume used and flared. The implication is that as the government and oil companies pursue their self-interest, specifically tax revenue and corporate profit respectively without mitigating the risk of burning gases, the people and the environment will continue to suffer the negative externalities. The little amount of fine on oil companies and inefficient enforcement of anti-flare regulations will keep flaring unabated for a long time if regulatory agencies fail to take practical actions.

The empirical results suggest that APG flare have verifiable impacts on the ecology and human health in the Niger Delta region. There is substantial evidence that gas flaring has led to environmental degradation and driven the crude death rate higher in the region. The impact of acidification on the ecology of the area should raise concern not only to conservationist but also to the government and the oil companies. The rising rate of chronic health issues including bronchial, chest, rheumatic and eye diseases reduces the life expectancy in the region which has a public health concern. The comparison of the crude death rate trends led credence that is plausible that there is a link between the gas flare and public health.

Flaring of APG has a severe economic implication, apart from the effects it has on the ecology and human health. The impact of APG flare can be mitigated by adopting appropriate technological options such as GTL, APG gathering systems, Gas treatment and process, on-site use (reinjection \& heat generation), conversion processing, and transportation. The cost-benefit analysis suggests that GTL seems to be the best solution to deploy in the region considering the technical feasibility, production capacity, cost-effectiveness, and the physical geography of the area. The suitability of other technological options is subject to further research. The flaring of APG poses a serious problem, but it has a sustainable technical solution that needs to be explored by the stakeholders to address the problems created by it.

\section{Acknowledgement}

First, we sincerely appreciate the editor and the anonymous reviewers of the earlier draft of this article for their comments. We acknowledge the helpful comments from Dr. James Peach; Regent Professor and Chevron Endowed Professor of the Economics, Applied Statistics \& International Business Department, New Mexico State University. We are thankful to Dr. Richard Adkisson; Chair Garrey and Katherine Carruthers Endowed Professor and Coordinator of the Doctor of Economic Development (DED) Program, and Dr. Chris Erickson, Professor and the Head Economics, Applied Statistics \& International Business Department, both of New Mexico State University. Our appreciation also goes to Dr. Megan Downes, Dr. Michael Patrick; the DED Program Director, and Dr. Steve Archambault for their encouragement. We also thank Bernard Bah-Kumi, a doctoral candidate at New Mexico State University for his criticism.

\section{Reference}

Adoki, A. (2012, March). Air Quality Survey of some locations in the Niger Delta Area. Journal of Applied Sciences and Environmental Management, 16(1), 125-134. 
Ake, C. (1979). The oil boom and its problems. (pp. 158-161). Nigeria Institute of Journalism. 8th Annual Oil Seminar.

Alakpodia, I. (2000). Soil Characteristics Under Gas Flares in Niger Delta, Southern Nigeria. Geo-Studies Forum, 1(1 and 2), 1-9.

Amann, M., Klimont, Z., Heyes, C., Scopp, W., Kiesewetter, G., Rafaj, P., ... Bertsen, T. (2017). Promising measures that achieve climate and air quality targets. International Institute for Applied System Analysis (IIASA). IIASA.

Ayansina, A., A., O. T., \& Odiong, A. (2010). Perception on Effect of Gas Flaring in the Environment. Research Journal of Environmental and Earth Sciences, 2(4), 188-193.

Banerjee, S., \& Toledano, P. (2016, July). A Policy Framework to Approach the Use of Associated Petroleum Gas. Columbia Center on Sustainable Investment.

Benka-Coker, M., \& Ekundayo, J. (1997). Applicability of evaluating the ability of microbes isolated from an oil spill site to degrade oil. Environmental Monitoring and Assessment, 45(3), 259-272. https://doi.org/10.1023/A:1005774602112

Callan, S. J., \& Thomas, J. M. (2013). Environmental Economics \& Management: Theory, Policy, And Applications (6 ed.). Mason, Ohio, USA: South-Western, Cengage Learning.

Carbon Limits AS. (2013). Associated Petroleum Gas Flaring Study for Russia, Kazakhstan, Turkmenistan and Azerbaijan. Oslo: Carbon Limits AS.

Christiansen, A., \& Haugland, T. (2009). Gas Flaring and Global Public Goods. Fridtjof Nansen Institute. Lysaker: Fridtjof Nansen Institute.

Clean Air Taskforce. (2015). Improving utilization of associated gas in US tight oil fields. Carbon Limits. Boston: Clean Air Taskforce.

Ehrhardt, M. C., \& Brigham, E. F. (2011). Financial Management: Theory and Practice. Mason, Ohio: South-Western Cengage Learning.

Emoyan, O., Akpoborie, I., \& Akporhonor, E. (2008, September). The Oil and Gas Industry and the Niger Delta: Implication for the Environment. Journal of Applied Science for Environmental Management, 12(3), 29-37.

Environment Canada. (2015, September 10). List of Toxic Substances Managed Under CEPA (Schedule 1). Retrieved November 28, 2015, from Environment Canada Web site: https://www.ec.gc.ca/toxiques-toxics/Default.asp?lang=En\&n=98E80CC6-1\&xml=34BCA9 B2-5EAF-4203-BB4D-5AAA517693F8

Feldman, U., Cheng, C., \& Doschek, G. A. (1982, April 1). Observational constraint for a theoretical model describing the soft X-ray flare. Astrophysical Journal, 255, 320-324. https://doi.org/10.1086/159832

Foster, H. (2010). Kazakhstan plans to end eco-unfriendly 'gas flaring' by 2012. Retrieved August 27, 2017, from Central Asia Newswire web site: 
https://test.universalnewswires.com/centralasia/kazakhstan-plansnbspto-end-eco-unfriendly-3 9gas-flaring39-by-2012/viewstory.

Gobo, A., Richard, G., \& Ubong, I. (2009). Health impact of gas flares on Igwuruta/Umuechem Communities in Rivers State. Journal of Applied Sciences and Environmental Management, 13(3).

Ifedi, C., \& Nwankwo, J. (1989). Critical Analysis of Oil Spill Incidents, Petroleum Industry and Nigerian Environment. Proceeding of 1982 International Oil Seminar (pp. 104-112). NNPC.

Ismail, S. O., \& Umukoro, E. G. (2012, July). Global Impact of Gas Flaring. Energy and Power Engineering, 4, 290-302. https://doi.org/10.4236/epe.2012.44039

Ite, A. E., \& Ibok, U. J. (2013). Gas Flaring and Venting Associated with Petroleum Exploration and Production in Nigeria's Niger Delta. American Journal of Environmental Protection, 1(4), 70-77. https://doi.org/10.12691/env-1-4-1

Justice in Nigeria Now. (2010). JINN's 2010 Report: Gas Flaring; an Overview. Oakland: Justice in Nigeria Now.

Karim, G., Rowe, R., \& Tollefson, E. (1985). A Review of Flaring in the Sour Gas Industry with Particular Reference to the Emission of Pollutants. Ottawa: The Environmental Protection Service of Environment Canada.

Lee, C., Kuchshenko, K., \& Carlsen, L. (2013). On a Possible Sustainable Petroleum Associated Gas Utilization in the Kashagan and Tengiz Regions, Kazakhstan. Euroasian Chemico Technological Journal, 15(2), 143-152. https://doi.org/10.18321/ectj152

McDaniel, M. (1983). Flare Efficiency Study. NC: Industrial Environmental Research Laboratory.

Nigerian National Petroleum Corporation(NNPC). (2014, July 30). Nigeria Gas Flared and Cost Implication. NNPC.

Nwaugo, V., Onyeagba, R., \& Nwahchukwu, N. (2005, October 2006). Effect of gas flaring on soil microbial spectrum in parts of Niger Delta area of southern Nigeria. African Journal of Biotechnology, 5(19), 1824-1826.

Odjugo, P., \& Osemwenkhae, E. (2009). Natural Gas Flaring Affects Microclimate and Maize (Zeamays) Yield. International Journal of Agriculture \& Biology, 11(4), 408-412.

Odu, C., Babalola, O., Udo, E., Ogunkunle, A., Bakare, T., \& Adeoye, G. (1986). Laboratory manual for agronomic studies in soil, plant and microbiology. Ibadan, Nigeria: University of Ibadan Press.

Pohl, J., Lee, J., Payne, R., \& Tichnenor, B. (1986). Combustion Efficiency of Flares. Combustion Science \& Technology, 50, 217-231.

https://doi.org/10.1080/00102208608923934 
Roland, T. H. (2010). Associated Petroleum Gas in Russia: Reasons for non-utilization. Fridtjof Nansens Institutt. Fridtjof Nansens Institutt.

Stokes, P. M. (1986). Ecological Effects of Acidification on Primary Producers in Aquatic System. Water, Air, and Soil Pollution, 30, 421-438. https://doi.org/10.1007/BF00305212

Strosher, M. T. (2000). Characterization of Emissions from Diffusion Flare Systems. Journal of the Air \& Waste Management Association, 50(10), 1723-1733.

https://doi.org/10.1080/10473289.2000.10464218

The American Association for the Advancement of Science; AAAS. (2015, July 13). Eyes on Nigeria: Gas Flaring. Retrieved September 6, 2015, from The American Association for the Advancement of Science(AAAS) Web site:

http://www.aaas.org/page/eyes-nigeria-gas-flaring

Toledona, P., Archibong, B., \& Korosteleva, J. (2014). Overview, Associated Petroleum Gas (APG). Columbia Center on Sustainable Investment. Columbia Center on Sustainable Investment.

U.S. Environmental Protection Agency (EPA). (2015, September 14). Sulfur Dioxide. Retrieved November 28, 2015, from EPA Web site:

http://www3.epa.gov/airquality/sulfurdioxide/

Ukala, E. (2011). Gas Flaring in Nigeria's Niger Delta: Failed Promises and Reviving Community Voices. Journal of Energy, Climate, and Environment, 97 -126. Retrieved from http://law2.wlu.edu/deptimages/journal

Urbaniak, D., Gerebicca, E., Vasse, G., \& Kocladze, M. (2007). Kashagan oilfield development. Friend of the Earth Europe.

van Dessel, J., \& Omuku, P. (1994). Environmental Impact of Exploration and Production Operations on the Niger Delata Mangrove. SPE Health, Safety and Environment in Oil and Gas Exploration and Production Conference, 25-27 January (pp. 437-447). Jakarta: Society of Petroleum Engineers.

World Bank. (2000/2001). Regulation of Associated Gas Flaring and Venting: A Global Overview and Lesson from International Experience. Washington DC: World Bank Group.

Zirin, H., \& Tanaka, K. (1981, Nov. 15). Magnetic transients in flares. Astrophysical Journal, 250, 791-795. https://doi.org/10.1086/159429

\section{Copyright Disclaimer}

Copyright for this article is retained by the author(s), with first publication rights granted to the journal.

This is an open-access article distributed under the terms and conditions of the Creative Commons Attribution license (http://creativecommons.org/licenses/by/3.0/). 